\title{
The Roles of Indigenous NGOs in Health Service Delivery in Ghana: Assessing the Mediating Effect of Administrative Authenticity on the Relationship Between Partnership Potential and Performance
}

\author{
Yuanwang Xu Edwina Naa Amerley Amarteifio Abredu Pearl \\ School of Management, Jiangsu University, Zhenjiang, 212013, China
}

\begin{abstract}
This study sought to investigate the features of local NGOs in Ghana and how their current status and challenges influence their potential for partnerships and sustained operation. Cross-sectional survey design was followed and ten health sector NGOs were engaged to respond to questions bordering funding, infrastructure, legalization/registration, and partnerships. Quantitative assessment of data and descriptive statistics was performed. Results showed that $60.0 \%$ of local NGOs lacked funding and $20 \%$ were not legalized/registered. Crosstabulation of data revealed that the lack of funding was explained up to $80.0 \%$ by NGOs' inability to register and legalize their operations. These challenges negatively impacted their ability to secure funding from donors in the health sector and government and as well hindered their partnership potential to a large extent and should be addressed.
\end{abstract}

Keywords: Local NGOs; partnership, health service delivery; sustainable development

DOI: $10.7176 /$ RHSS/9-22-03

Publication date: November $30^{\text {th }} 2019$

\section{Introduction}

For over several decades up till now, NGOs have played an increasingly prominent role in the development sector and are globally appreciated for their contributions especially in fighting for the course of the marginalized and poor of society (Kucheryavaya, 2017; Trejos et al., 2008). These organizations, described by their objectives or by other features that separate them from traditional state functioning organizations, are known for their innovative characteristics and the fact that they believe in localized or grassroot approaches with a common desire. They also have the ability to plan and organize development activities that are participatory and people-centered in nature and to fill gaps left by the failure of public departments across the developing world in meeting the needs of their poorest citizens (Banks \& Hulme, 2012; Bebbington et al., 2008). The cost of developing countries' institutional weaknesses, which often include shortcomings in administration and lack of capacity to efficiently undertake important development tasks, are mitigated by the activities of NGOs (Ibrahim, 2017). While levels of funding for NGO programs in service delivery and advocacy work have increased alongside the rising prevalence and prominence of NGOs, concerns regarding the effectiveness of their actions have also increased. Given the fact that they are non-governmental in nature, their non-political characteristics have rendered them of little effect in terms of their participation and/or impact in tackling the more politically oriented causes and manifestations of poverty and poor health delivery in Ghana. The concern to assess the roles played by NGOs in bridging the health delivery gap is a necessity to understanding the issues on the ground, the challenges and finding lasting solutions.

Past publications in Ghanaian news items on international health NGOs in Ghana have shown that, NGOs offer great support in areas such as nutrition, malaria prevention and treatment, HIV/AIDS, and water and hygiene (Arhin, 2016). Some of these efforts lead to the formulation of policies, encouraging the formation of a working network among related health NGOs in Ghana. The reason for such a network is to ensure some form of organization and communication in order to avoid the repetition of health service delivery efforts of NGOs in a given location by another NGO. The Ghana Coalition of NGOs in Health (GCNH), a civil society organization (CSO), was formed as an umbrella secretariat which oversees the operations of all registered NGOs, both local and international. This development enhanced cooperation between the ministry of health of Ghana's government and the NGOs among other collaborative benefits. Despite the effort to enhance work and partnership among NGOs and to create the synergy needed, there seems to be a huge gap concerning the position of indigenous NGOs and their roles played. It is easier relatively to find information on international NGOs working in the health sector in Ghana than on local NGOs. Known international NGOs such as Action Aid Ghana, World Vision, Action for Disability and Development, Planned Parenthood Association of Ghana, and Christian Children's Fund of Canada and Adventist Development and Relief Agency are easy to capture in literature whereas local NGOs are nowhere to be found. It suffices to say that although the activities of international NGOs in the developing regions of the world have gained extensive attention in literature, the contributions of indigenous civil society organizations (CSOs) have gone largely unnoticed and given 
significantly less attention. Factually, there are several of such local NGOs and other CSOs making positive contributions within their respective communities, but are not recognized beyond their borders. A unique feature characteristic of these local NGOs, which is not that prominent in their international counterparts is their capacity to tap local human, cultural and physical resources to respond rapidly and creatively to problems (Arhin et al., 2018; Badu \& Parker, 1994). The flexibility with which these local NGOs are able to perform their activities under changing socio-economic settings is an added strength that makes probing into their roles in sustainable development in the developing world crucial (Badu \& Parker, 1994).

The potential for partnership for local NGOs cannot be overemphasized as crucial in recent times considering the increasing need for support for improved health delivery in local communities in Ghana. BelloBravo and Amoa-Mensa (2019) documented how a local Ghanaian cocoa sector SME partnered with a Ghanaian NGO to resolve challenges related to certification and other legal requirements which led to its success in operating in Ghana. This is one example of many partnerships that have yielded good returns for local enterprises in Ghana. However, the developing and dynamic landscape in Ghana presents several challenges to the development of NGOs and to their effective contribution to the Ghanaian economy (Arhin et al., 2018). From lessons drawn on detailed qualitative interrogations with some Ghanaian NGOs, Arhin (2016) contended that expectations of the roles of most NGOs in Ghana in advancing the cause of development are being affected by uncertainty of income generation and funding sources; changing operational capacity; and changing NGO identity. In recent times, research has shown that at least $70 \%$ of NGOs in Ghana obtain their sources of funding from foreign donations and assistance from Ghana's bilateral and multilateral partners (Arhin et al., 2015). Another study undertaken in 2017 found that the magnitude of external donor funding was about $90 \%$ of the total budgets of NGOs in three Ghanaian regions (i.e. Upper West, Northern and Greater Accra) (Arhin, 2016). Such findings have thrown light on the issue of donor funding but little is said about the ability of indigenous NGOs and how much they are able to get in the form of support from such kinds of donations. Another question is about whether or not they have the institutional structures to access such financial supports, taking into account the complex nature of funding agreements and requirements from international donors. Although several research works are focusing on how NGOs are performing, less is being done about understanding the challenges faced by indigenous NGOs and what they need in order to operate successfully. A comprehensive assessment of their strengths, weaknesses, opportunities and threats (SWOT) is lacking in literature. This study therefore seeks to address the problem of lack of information on the contribution of local NGOs and also assess their roles and challenges in the delivery of health services in Ghana.

\section{Methodology}

2.1 Sampling and data collection

Cross-sectional data were collected from twenty-five (25) local NGOs working in the health sector of Ghana using structured questionnaires administered by face-to-face mode. Fifteen (15) purposively sampled respondents who were in top administrative positions of the selected local NGOs took part in the data collection process, totaling three-hundred and seventy-five (375). This study followed a qualitative design and the main focus was to find out what specific interventions they have participated in or carried out in the delivery of health services as well as what challenges they faced in doing so smoothly and in partnering on health service delivery with either international NGOs and/or government of Ghana.

\subsection{Data analysis}

Data were organized using statistical package for social scientists (SPSS, version 20) and results were presented in Tables and Figures. Descriptive statistics was performed, specifically, frequency distributions, correlations and crosstabulations were used to probe data for better understanding. Data were also assessed using the PROCESS macro function in SPSS as described by Hayes' (2018) and multiple linear regression to establish the relationships between all variables (Figure 1) and the mediating function of employee work engagement (WE) and results presented in Tables and Figures. 


\subsection{Framework for NGO assessment}

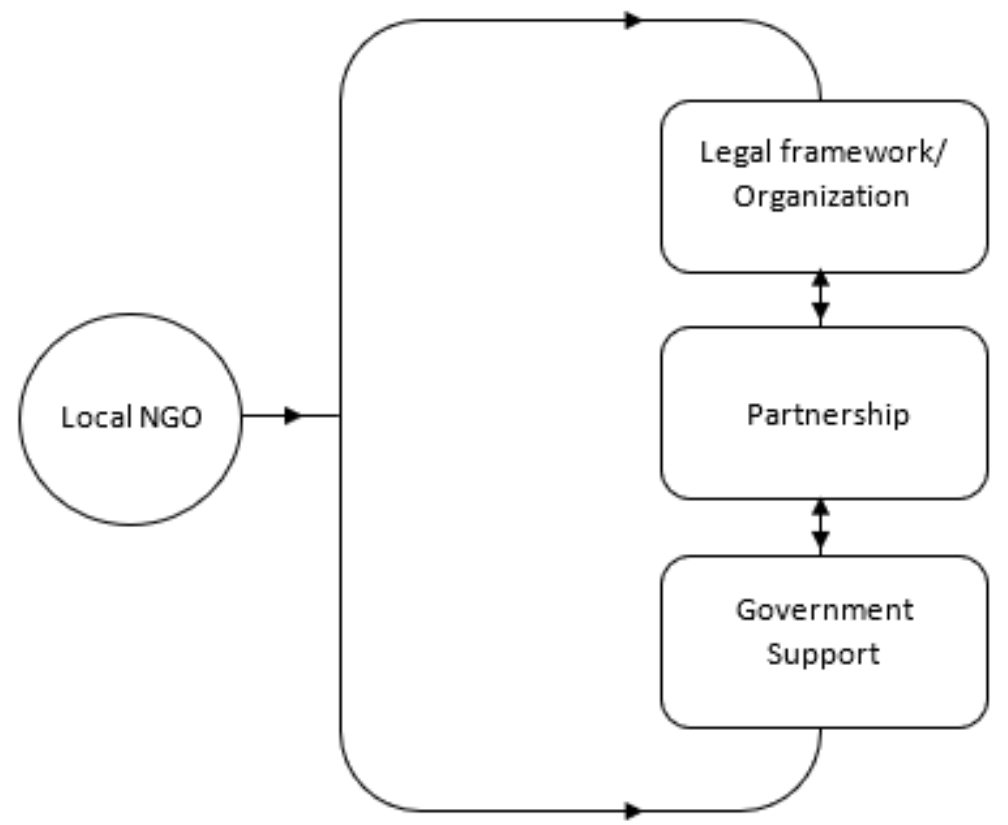

Figure 1: Conceptualization of the features of local NGOs that influence their relationship with actors

From this framework, the study develops an argument based on the features of legal framework/ organization which encompasses the legal administration and registration of the $\mathrm{NGO}$, the availability of structures that gives it the necessary support to operate without impediments from policies, laws and regulations (Fritz, 2008; Mostashari, 2005). This feature also puts them in the position to be able to source funding from donors, without which authenticity would be problematic. The second feature that was assessed by this study considers whether or not this NGO has ever partnered either with international, local or any government department in Ghana and what the scope of partnership was in detail. The second is concerned with any forms of government support, either logistically, human resource-wise or financially without necessary interferences with the administration of the project supported by government.

2.4 Conceptualization of the relationship between variables

The predictor variables of the construct are partnership potential (PP) and administrative authenticity (AA) and the response variable is NGO performance (P) (Figure 2). Th indirect or mediation relationship is depicted in dotted lines whereas the direct relationship is indicated in full lines.

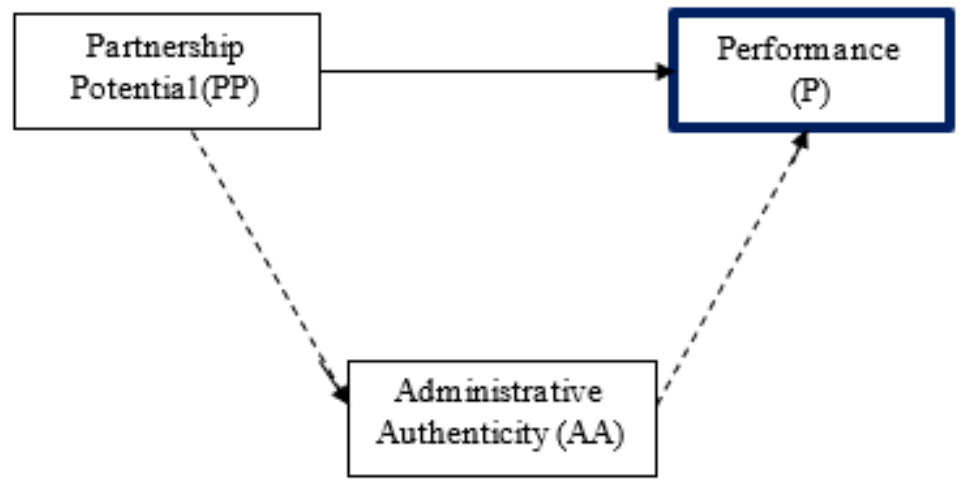

Figure 2: Direct and indirect or mediating relationships between variables

\section{Results and discussion}

4.1 Demographic information

All questionnaires $(100 \%)$ were retrieved and all respondents were managers of their respective local NGOs with ages ranging between $30-40(60 \%), 41-50(30 \%)$ and $51-60(10 \%)$. Majority of respondents were male $(70 \%)$ and fell between 30 and 40 years of age (Table 1$)$. 


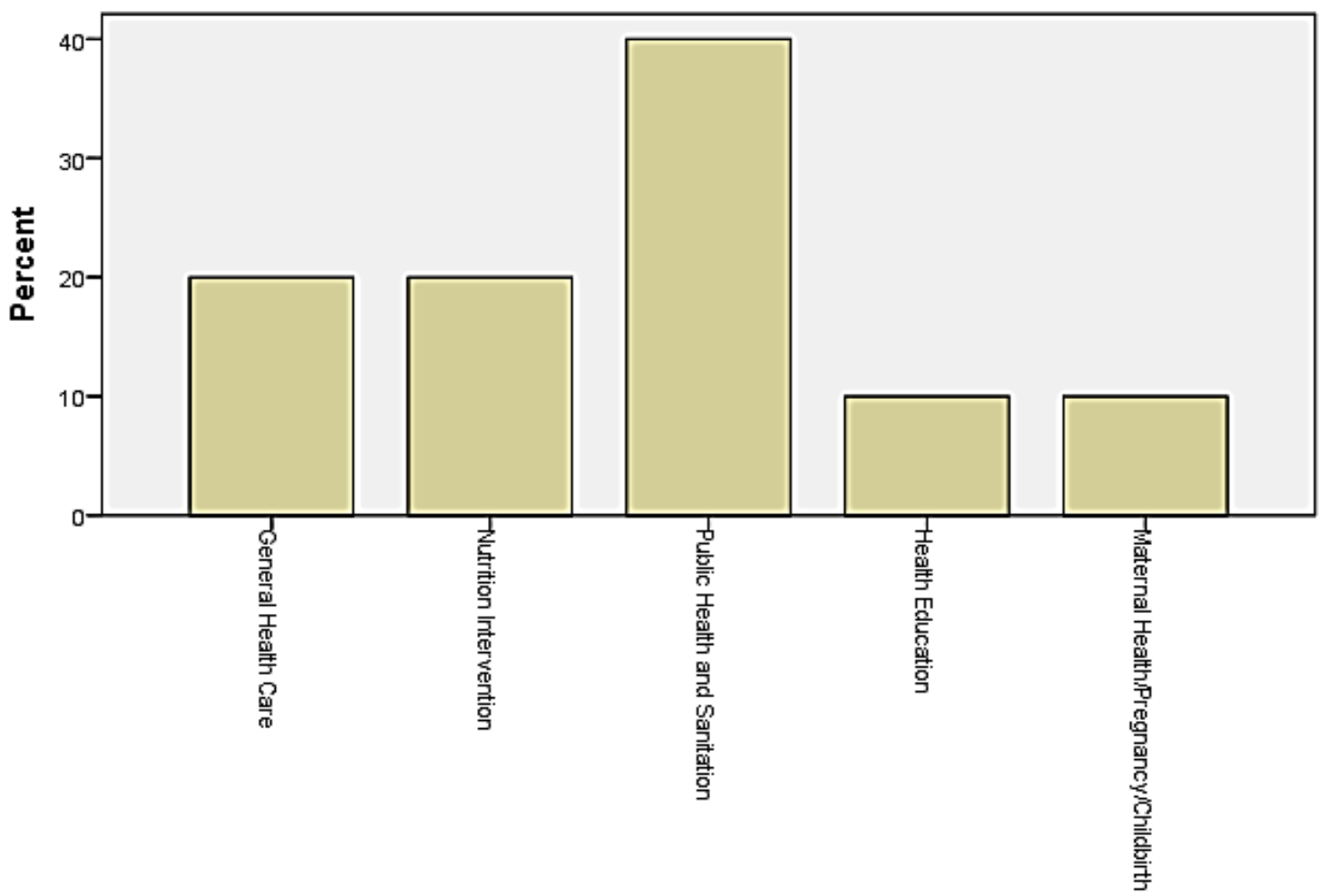

Table 1: Demographic information on respondents (age, gender and education level)

\begin{tabular}{llcc}
\hline & & Frequency & Percentage (\%) \\
\hline Age & {$[\mathbf{3 0}-\mathbf{4 0 ]}$} & 6 & 60 \\
& {$[\mathbf{4 1}-\mathbf{5 0 ]}$} & 3 & 30 \\
\multirow{4}{*}{ Gender } & {$[\mathbf{5 1}-\mathbf{6 0}]$} & 1 & 10 \\
\multirow{3}{*}{ Level of education } & Male & 7 & 70 \\
& Female & 3 & 30 \\
& Secondary & 2 & 20 \\
& Vocational & 2 & 20 \\
& Tertiary & 6 & 60 \\
\hline
\end{tabular}

This sharp difference between the number of male and female managers of local NGOs engaged in this study reflects the gender landscape within the working class in Ghana (Awumbila, 2006). Generally, more men occupy managerial positions in Ghanaian firms than women. Majority of respondents, who are managers of the local NGOs engaged in this study had tertiary education, most of whom were first degree holders $(67 \%)$ and the remaining had master degrees $(33 \%)$.

4.2 Major activities of local NGOs engaged in this study

Although all local NGOs engaged in this study were working in the health sector or had their main focus being health related, a further sub-classification of their activities revealed that majority of them were into public health and sanitation (40\%), followed by general health care $(20 \%)$, nutrition $(20 \%)$, maternal and childbirth $(10 \%)$ as well as health education (10\%) (Figure 2). It was noted from crosstabulation that majority $(80 \%)$ of local NGOs engaged in public health and sanitation were also into health education. It can be noted from literature that almost all the NGOs working in the health-related sector in Ghana, major in programs surrounding nutrition, maternal health, public health, hygiene and sanitation (https://www.vconnect.com/ghana/list-ofngos_c459). This observation is not much different from that of local NGOs in this study although information in literature mostly covered international NGOs than local ones.

Figure 2: Main activities of local NGOs in health service delivery in Ghana

4.3 Sources of funding for NGO health related activities

Most of the funding sources of the local NGOs were contributions from internally generated income from commercial activities $(20 \%)$, support from international NGOs working in health-related fields $(20 \%)$, and contributions from community (20\%) (Figure 3). Racelis (2008) also wrote on how NGOs partner with their local communities. None of the local NGOs mentioned being supported financially in any way by donor organizations unlike for international NGOs operating in Ghana (Arhin, 2016; Banks, 2011). This may be due to 
their inability to meet donor requirements or the lack of capability to market or advertise themselves to potential donors (Fritz, 2008; Mostashari, 2005). It could also be as a result of low level or lack of visibility that most local NGOs suffer from or their inability to partner funding agencies with similar missions (ICNL, 2018).

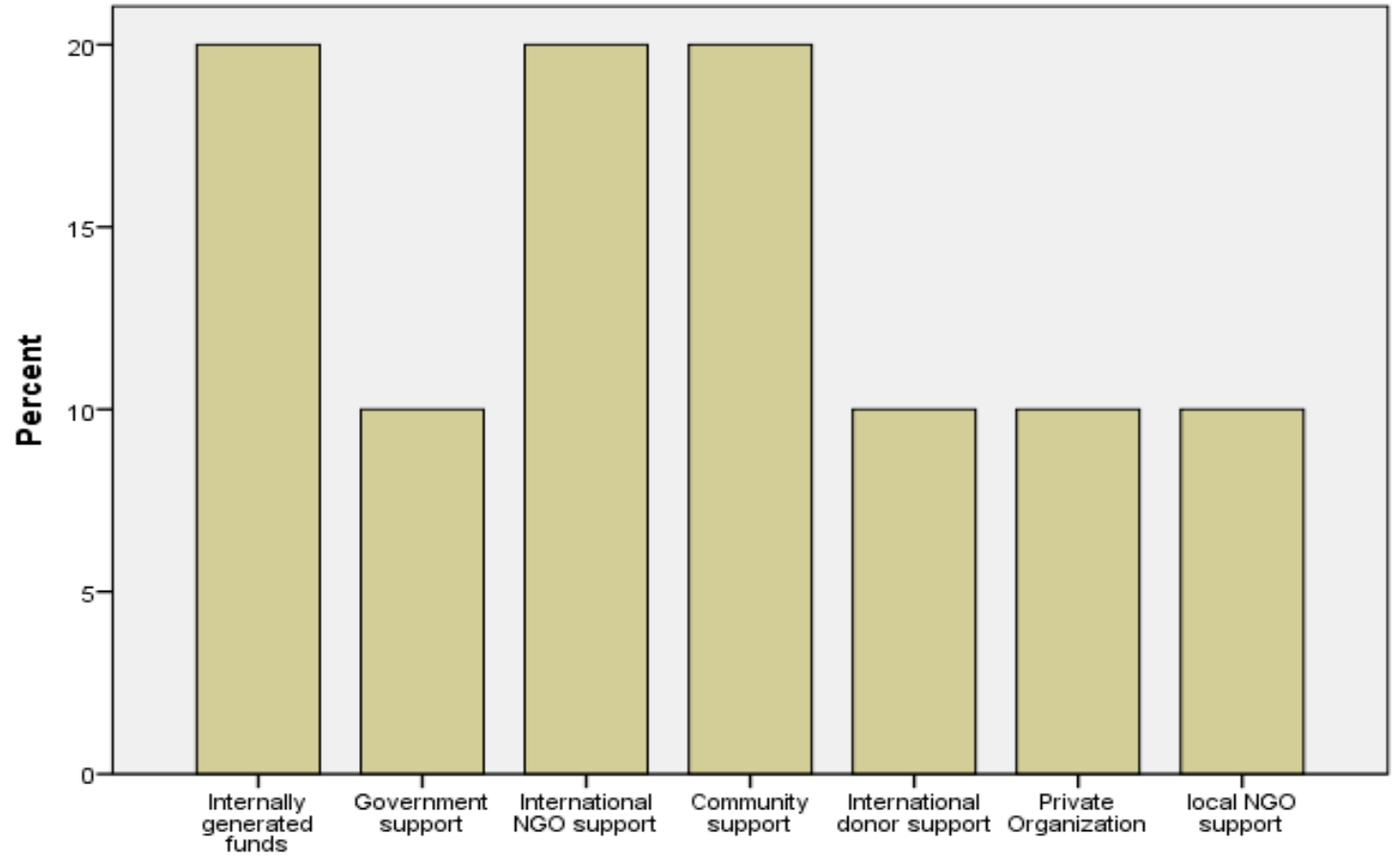

Figure 3: Sources of funding for local NGO activities and projects

4.4 Local NGO partnership in health service delivery

Most of the local NGOs (60\%) engaged in this study have not had any form of partnerships to undertake projects in health service delivery. This may still be linked to their lack of preparation to undertake meaningful projects by contributing to the strengths or making up for the weaknesses of potential partners (Brass, 2011; Coreau, 2017; Foo, 2018). Partners look out for complementary organizations to partner and anything less than that is likely not to enhance meaningful partnerships (Gupta \& Koontz, 2019). The remaining $40 \%$ of local NGOs in this study who have entered some sort of partnership partnered mainly community groups (50\%) (Figure 4). Both local and international NGOs were also partnered to an equal level $(20 \%)$ and the least means of partnership was with private organizations (10\%) which were not even donor agencies (Figure 4$)$.

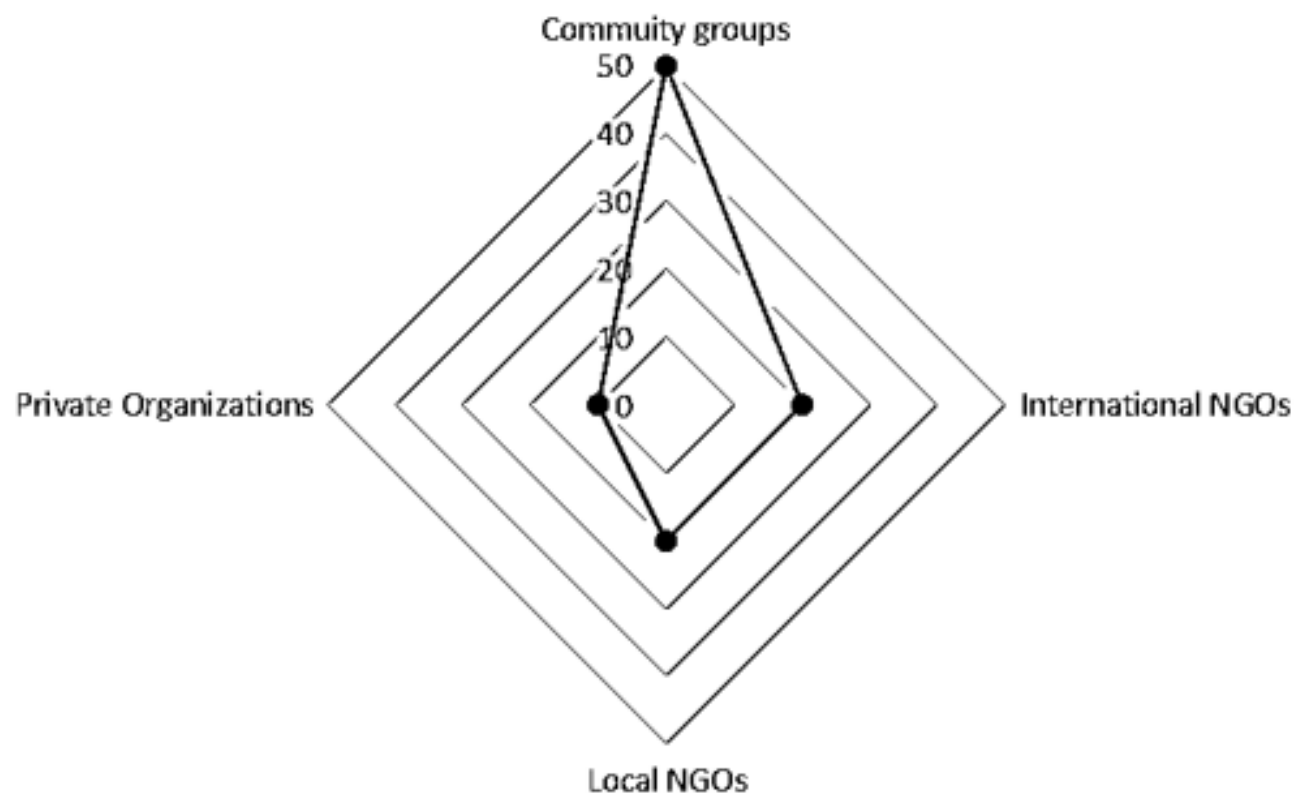

Figure 4: Entities and groups local NGOs have been able to partner 
4.5 Strengths, weaknesses and challenges of local NGOs in the health sector

The strengths of any organization show them to features which can be harnessed for the success and sustainable development in both the short and long term. Weakness assessments are needed to show organizations to those aspects that can be further worked upon and strengthened through strategic approaches such as training, reforms and entire transformation if necessary (Maqbool et al., 2014). The main strengths that the local NGOs confirmed to have are their access to rich sources of indigenous knowledge (40\%), ability to mobilize community support $(30 \%)$ and innovative means of achieving results using cheap but acceptable means (20\%) (Table 2). From results so far, the local NGOs studied in this work have shown various types of weaknesses, and these explain why they face many challenges, especially regarding their ability to source sufficient funding to run their operations in Ghana (Table 2). These weaknesses also underpin their inability to engage and sustain profitable partnerships (Gupta \& Koontz, 2019). The main weakness that seems to run trough all ten (10) NGOs is the fact that they lack sufficient funding $(50 \%)$ to undertake activities towards the realizations of the goals for which they exist. They are unable to execute health service delivery programs effectively due to this same challenge.

Table 2: Strengths and weaknesses of local NGOs engaged in this study

\begin{tabular}{lc}
\hline Strengths of Local NGOs & Percentage (\%) \\
\hline Innovative with cheap but efficient strategies & 20 \\
Ability to mobilize community support & 30 \\
Access to indigenous knowledge & 40 \\
High level of education & 10 \\
\hline Weaknesses of local NGOs & \\
\hline Lack of funding & Percentage (\%) \\
Lack of infrastructure & 50 \\
No legalization/ registration of NGO & 20 \\
Low education level of members & 20 \\
\hline
\end{tabular}

The weaknesses of the NGOs studied in this work are reflected in their challenges as depicted in Figure 5. The lack of funding $(60 \%)$ as a challenge correlates positively with their inability to secure funding $(50 \%)$ for their projects (Compare Table 2 with Figure 5). The next challenge that seems to have significant effect on the operation of local NGOs in Ghana is their inability to acquire legal certificates to operate as registered organizations. Up to $20 \%$ of NGOs studied have not been able to legalize and register their operations (Figure 5). This, in itself is a disadvantage and renders the local NGOs non-competitive and unqualified to solicit for donor funding or to partner with government and other NGOs on relevant projects (Batley, 2011; Brass, 2012). Despite their strengths and ability to deliver health care services, their non-official existence and operations make smooth administration of projects difficult in general terms.

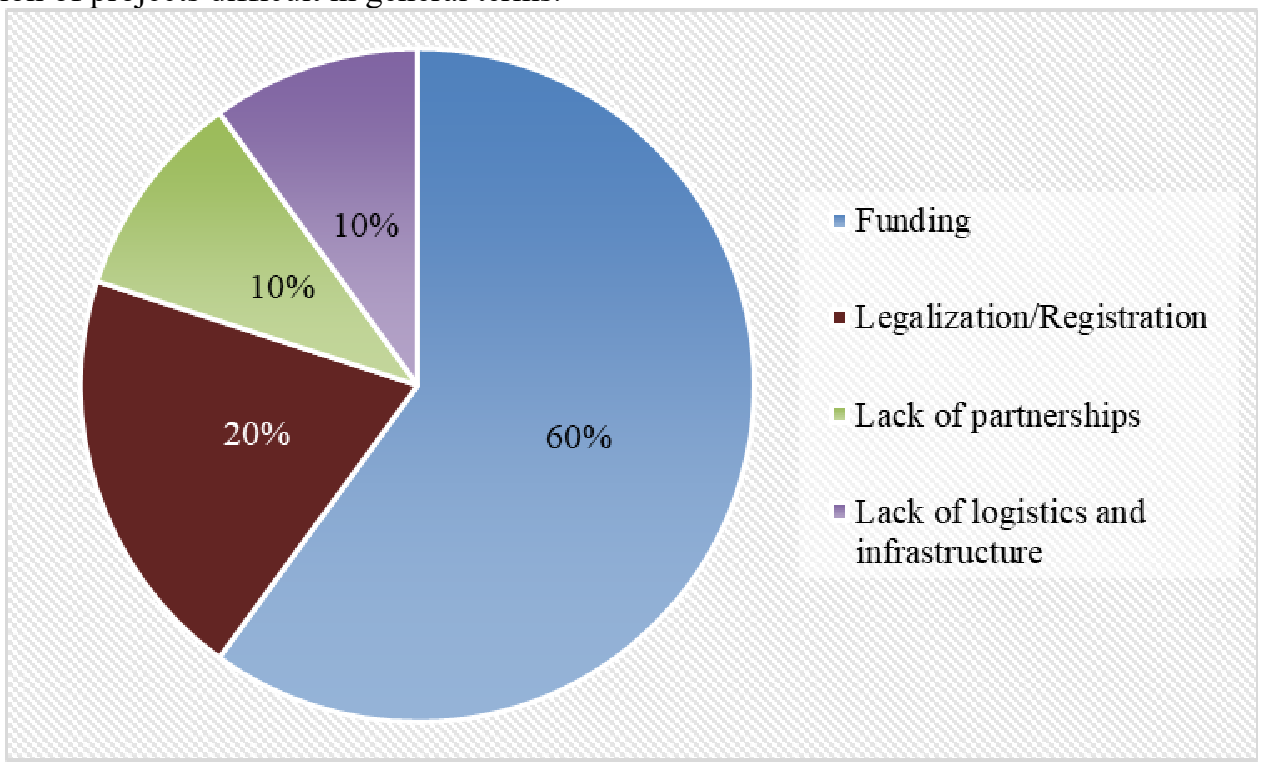

Figure 5: Main challenges face by local NGOs engaged in this study

From results, it can be observed that challenges with partnership and infrastructure can be better managed if local NGOs get themselves registered and legalized to put them in the position for better partnerships and for competitive bidding for funding from donor agencies and government. Taking care of their legalization/registration needs has the potential to greatly improve their financial standing and other areas. 
4.6 Test of mediation of administrative authenticity

A significant number of firms in the study have not legalized their existence administratively, and so are regarded as non-authentic or having poor administrative authenticity to operate. It is assumed in the study that this challenge may have a significant effect on the relationship between NGOs' partnership potential and performance. This test therefore was conducted to ascertain if such a mediation role of administrative authenticity existed, using the PROCESS Macro application in IBM SPSS, version 25, as described by Hayes (2018).

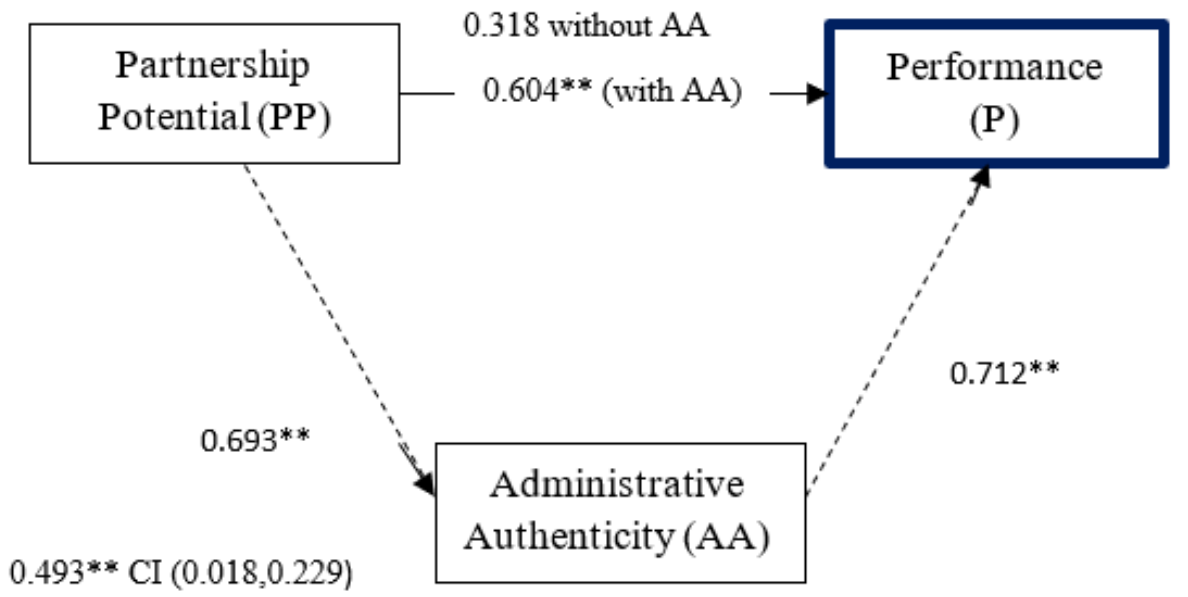

The model for assessing mediation was significant $(\mathrm{P}<0.05)$ and analysis carried out by the PROCESS macro SPSS application did not show any mediation effect of AA on the relationship between PP and P. The indirect effect coefficient of mediation was 0.493 with lower and upper confidence intervals being 0.0180 and 0.2290 respectively. The mediation coefficient was higher than the direct effect coefficient of PP (0.318) on P, showing that there was a significant mediating effect of AA on the relationship between PP and P (Figure 4). It can also be seen that, without considering the effect of AA, PP was only able to explain the variability in P by $31.8 \%$ whereas it did better with a $60.4 \%$ when AA was considered, another confirmation that AA was relevant in predicting the relationship between PP and P among NGOs studied.

The relevance of partnership potential cannot be overemphasized because it is a key means of leveraging one's resources and strengths and covering up weaknesses with the strengths of others (Besley \& Ghatak, 2017). Public private partnerships have been the subject matter in the development sector for the past two decades now and it is one of the means by which NGOs are administered in the midst of scarce resources (Anagal, 2014; Citrin et al., 2018).

\section{Conclusion}

Local NGOs working in the health sector in Ghana were assessed in this study. Their current status and challenges were investigated and how these influenced their potential for partnerships and sustained operation were ascertained. The role of these NGOs was assessed considering how they fared in areas bordering funding, infrastructure, legalization/registration, and partnerships. Quantitative assessment of data and descriptive statistics showed that $60.0 \%$ of local NGOs lacked funding and $20 \%$ were not legalized/registered. Results further revealed that the lack of funding was explained up to $80.0 \%$ by NGOs' inability to register and legalize their operations. These challenges negatively impacted their ability to secure funding from donors in the health sector and government and as well hindered their partnership potential to a large extent and should be addressed. A strong correlation was realized between PP and P when AA was taken into consideration and this suggests that in establishing the relevance of partnerships among NGOs, it is important that their setups are administratively authentic. Thus, efforts towards the registration and legalization of NGOs in the health delivery sector has the potential to improve their performance by more than $60 \%$.

\section{References}

1. Anagal, V. (2014). Role of NGO, PPP in infrastructure management. Available at: file://C:/Users/Sedem/Downloads/RoleofNGOPPPinurbaninfrastructure.pdf. Accessed 21/04/2019 at 19:28.

2. Arhin, A. (2016). Advancing post-2015 Sustainable Development Goals in a changing development landscape: Challenges of NGOs in Ghana. Development in practice. https://doi.org/10.1080/09614524.2016.1189513.

3. Arhin, A.A., Kumi, E., \& Mohammed-Anwar, S.A. (2018). Facing the Bullet? Non-Governmental 
Organizations' (NGOs') Responses to the Changing Aid Landscape in Ghana. Voluntas, 29, 348-360. https://doi.org/10.1007/s11266-018-9966-1.

4. Banks, N., \& Hulme, D. (2012). The role of NGOs and civil society in development and poverty reduction. Brooks World Poverty Institute. Available at https://www.cid.org.nz/assets/2015-Role-ofNGOs-Civil-Society-in-Development-2012.pdf. Accessed 22/03/2019 at 14:05.

5. Banks, N., (2011). Improving donor support for urban poverty reduction: a focus on South Asia. UNUWIDER Working Paper No. 2011/68.

6. Batley, R. (2011). Structures and strategies in relationships between non-government service providers and governments. Public Administration and Development, 31, 306- 319.

7. Bebbington, A. J., Hickey S., \& Mitlin, D. (2008). Introduction: can NGOs make a difference? The challenge of development alternatives. In: A. J. Bebbington, S. Hickey, and D. C. Mitlin (eds.). Can NGOs Make a Difference? The Challenge of Development Alternatives, London: Zed Books, pp3-37.

8. Bello-Bravo, J., \& Amoa-Mensa, S. (2019). Scaffolding entrepreneurship: a local SME-NGO partnership to enable cocoa production in Ghana. Journal of Small Business \& Entrepreneurship. https://doi.org/10.1080/08276331.2018.1528138.

9. Besley, T., \& Ghatak, M. (2017). Public-private partnerships for the provision of public goods: Theory and an application to NGOs. Research in Economics, 71, 356-371. http://dx.doi.org/10.1016/j.rie.2017.04.005.

10. Brass, J. N. (2011). Blurring boundaries: the integration of NGOs into governance in Kenya. Governance: An International Journal of Policy, Administration, and Institutions, 25(2), 209-235.

11. Brass, J.N. (2012). Why do NGOs go where they go? Evidence from Kenya. World Development, 40(2), 387-401.

12. Citrin, D., Bista, H., \& Mahat, A. (2018). NGOs, partnerships, and public-private discontent in Nepal's health care sector. Medicine Anthropology Theory, 5(2), 100-126. https://doi.org/10.17157/mat.5.2.529.

13. Coreau, A. (2017). Reflexive strategic action to consolidate a research-NGO partnership during science-policy interactions. Environmental Science \& Policy. https://doi.org/10.1016/j.envsci.2017.03.006.

14. Foo, K. (2018). Examining the Role of NGOs in urban environmental governance. Cities, 77, 67-72. https://doi.org/10.1016/j.cities.2018.01.002.

15. Fritz, J. (2008). How to Incorporate as a Nonprofit: A Check List. Available at http://nonprofit.about.com/od/nonprofitbasics/ht/startingsteps.htm?nl=1. Accessed 17/03/2019 at 14:35.

16. Gupta, D., \& Koontz, T.M. (2019). Working together? Synergies in government and NGO roles for community forestry in the Indian Himalayas. World Development, 114, 326-340. https://doi.org/10.1016/j.worlddev.2018.09.016.

17. Hayes, A. F. (2018). Introduction to mediation, moderation, and conditional process analysis: A regression-based approach (2nd edition). New York: The Guilford Press.

18. Ibrahim, H.A. (2017). NGOs and development work in developing countries: a critical review. American Journal of Innovative Research and Applied Sciences, 5(1), 1-6.

19. Kucheryavaya, E.V. (2017). The Role of NGOs in the Development of Societies and Overcoming the Consequences of Crises: Case Studies of Poland and Russia. Polish Political Science Yearbook, 45, 166-177. https://doi.org/10.15804/ppsy2016013.

20. Maqbool, L., Ahmed, N., Hayyat, M.U., Mahmood, R., Haider, Z., \& Nawaz, R. (2014). Strengths, weaknesses, opportunities and threats (SWOT) analysis of Environmental NGOs working in Punjab, Pakistan. Int. NGOJ., 9(1), 11-16. https://doi.org/10.5897/INGOJ2013.0283.

21. Mostashari, A. (2005). An Introduction to Non-Governmental Organizations (NGO) Management. Available at http://web.mit.edu/isg/NGOManagement.pdf. Accessed 17/03/2019 at 14:39.

22. Racelis, M. (2008). Anxieties and affirmations: NGO-donor partnerships for social transformation. In: A. Bebbington, S. Hickey and D. Mitlin (eds.). Can NGOs Make a Difference? The Challenge of Development Alternatives, London and New York: Zed Books, pp. 196-218.

23. Trejos, B., Huang, W-C., Chiang, L-H.N. (2008). The Role of NGOs in the Development of Community-Based Rural Tourism in Costa Rica. Journal of Rural Tourism Research, 2(1), 63-76.

24. Vconnect (2019). List of NGOs in Ghana. Available at https:/www.vconnect.com/ghana/list-ofngos_c459. Accessed 22/03/2019 at 15:08. 